\title{
Identifying a Personalized Anesthetic with Fuzzy PROMETHEE
}

\author{
Ilker Ozsahin ${ }^{1,2}$ \\ 'Department of Biomedical Engineering, Faculty of Engineering, Near East University, Nicosia/TRNC, Mersin, Turkey \\ ${ }^{2}$ DESAM Institute, Near East University, Nicosia/TRNC, Mersin, Turkey
}

Objectives: During an anesthetic evaluation, the individual's medical history and overall fitness for the whole medical procedure should be carefully examined. The objective of this study was to apply a multi-criteria decision-making technique to determine the proper anesthetic agent for specific patients. Methods: The fuzzy PROMETHEE (Preference Ranking Organization Method for Enrichment of Evaluations) method was applied to determine the most appropriate agent. Minimum alveolar concentration, blood:gas and oil:gas partition coefficients, onset of action, recovery time, duration, induction and maintenance doses, and washout time were used as the criteria for the analysis. After defining the values of each criteria, the criteria weights and the preference function were set, and finally the results for two different examples, one for general ranking and one for a specific individual were obtained. Results: The results show that nitrous oxide and xenon are among the preferred inhaled anesthetics in the ranking of the inhaled anesthetics, whereas midazolam was identified as the preferred injected agent. When the weights are selected according to a specific patient's condition, namely a 70-year-old woman to undergo an emergent laparoscopic appendectomy with comorbidities, including severe chronic obstructive pulmonary disease as a consequence of a life-long smoking habit, morbid obesity, and type II diabetes, the results changed significantly. In this case, desflurane and etomidate come first in the ranking of inhaled and injected anesthetics, respectively, while nitrous oxide is the least preferred anesthetic agent. Conclusions: Expert opinion is always needed. Assigning weights to criteria and grading alternatives are the major challenges in multi-criteria decision-making studies. Fuzzy PROMETHEE is proposed to solve a multi-criteria decision-making problem in selecting a general anesthetic.

Keywords: General Anesthesia, Anesthetic Agents, Clinical Decision-Making, Nitrous Oxide, Xenon

Submitted: May 27, 2020

Revised: July 10, 2020

Accepted: July 20, 2020

\section{Corresponding Author}

Ilker Ozsahin

Department of Biomedical Engineering, Faculty of Engineering, Near East University, Nicosia/TRNC, Mersin-10 TRNC, 99138 Turkey. Tel: +90-533-876-7925, E-mail: ilkerozsahin@windowslive.com (http://orcid.org/0000-0002-3141-6805)

This is an Open Access article distributed under the terms of the Creative Commons Attribution Non-Commercial License (http://creativecommons.org/licenses/by$\mathrm{nc} / 4.0 /$ ) which permits unrestricted non-commercial use, distribution, and reproduction in any medium, provided the original work is properly cited.

(c) 2020 The Korean Society of Medical Informatics

\section{Introduction}

The general anesthetic effect, ideally, produces a loss of all sensations, including analgesia and muscle relaxation. The characteristics of an ideal anesthetic agent include rapid and pleasant induction and recovery, adequate potency and muscle relaxation, and a wide margin of safety. Moreover, it should have no toxicity or reactivity issues, and it should not cause any adverse side effects [1]. However, currently no drugs can fulfill all the requirements because the choice depends on the type and duration of the operation; the method of anesthetic administration, such as intravenous injection or inhalation; side effects; cost; and patient characteristics, 
such as age, sex, weight, and pathophysiology. Therefore, the anesthetist or anesthesiologist would determine the appropriate anesthetic agents prior to an operation for each individual to maximize the patient's comfort while minimizing the patient's risks, i.e., morbidity and mortality as well as drug side effects [2]. During an anesthetic evaluation, apart from the aforementioned factors, the individual's medical history and overall fitness for the whole medical procedure, including their cardiac and pulmonary functions as well as the likelihood of any adverse reactions to anesthetics are assessed to develop an effective anesthetic plan tailored for them in a cost-effective manner [3].

Differences between age groups is one important factor to consider during the selection of an anesthetic agent. Because a greater number of elderly patients require surgery than any other group, geriatric patients need more attention in the evaluation of their anesthetic requirements. Infants, pediatrics, adults, and geriatrics have different pharmacodynamics and pharmacokinetics due to differences in body composition, cardiac output, metabolic rate, and so forth. Therefore, each age group requires individual evaluations.

More importantly, evaluating each individual's condition according to the American Society of Anesthesiologists (ASA) physical status classification system is of vital importance. In the ASA classification, anesthesiologists assign patients to a group considering not only their physical and physiological fitness, but also factors such as age, obesity, tobacco use, and recovery from a condition like myocardial infarction.

In this regard, multi-criteria decision-making systems based on human knowledge can be applied to the selection of general anesthetics. The fuzzy Preference Ranking Organization Method for Enrichment of Evaluations (PROMETHEE) decision-making method is a concept based on the evaluation and comparison of complex and multiple criteria, with the advantage of easy implementation in comparison to other multi-criteria decision-making systems [4]. To the best of my knowledge, no applications of the fuzzy PROMETHEE methodology for the determination of anesthetic agents have been proposed in the existing literature. In this paper, I propose the use of fuzzy PROMETHEE to compare, evaluate, and rank general anesthetics based on the physical parameters and assigned importance of commonly known drugs.

\section{Methods}

\section{General Anesthetics Parameters}

General anesthetics parameters influence the characteristics and suitability of agents. They are listed for inhaled and injected anesthetics separately because certain parameters are unique to only one but not the other.

\section{1) MAC (for inhaled anesthetics only)}

The minimum alveolar concentration (MAC) is defined as the concentration at 1 atmosphere of inhaled anesthetic in the alveoli, which produces immobility in $50 \%$ of individuals (adults) exposed to a standard surgical incision [5]. The MAC gives a measure of the potency of anesthetics; therefore, it is used to compare the strength and effectiveness of inhaled agents at equipotent doses. It is important to note that potency and MAC values are inversely proportional; hence, the more potent an agent is, the lower its MAC value is.

2) Blood:gas partition coefficient (for inhaled anesthetics only) The blood:gas partition coefficient is a term that refers to the solubility of inhaled anesthetics in the blood [6]. It is a measure of the solubility of an agent in the blood relative to its solubility in the inspired air. As the solubility of an agent increases (high blood:gas partition coefficient), larger amounts of the agent are needed to dissolve in the blood before being delivered to the brain where it can exert its effect. Therefore, agents with lower blood:gas partition coefficients are desired as they have more rapid onsets of action of anesthesia and faster elimination rates from the body [7].

3) Oil:gas partition coefficient (for inhaled anesthetics only) Another important partition coefficient that refers to the solubility of inhaled anesthetic agents in the body is the oil:gas partition coefficient. The value of this coefficient is determined by the lipid solubility of agents and is directly linked with the potency of anesthetics [8].

\section{4) Onset of action (for both)}

Onset of action refers to the time it takes for anesthetic agents to be delivered to the central nervous system (CNS) and start exerting their effects once they are administered. Agents with rapid and smooth induction are preferred over slow onset agents.

5) Recovery time (for inhaled anesthetics only)

Recovery from anesthesia results from the elimination of 
anesthetic agents from the CNS once they are discontinued; thus, the recovery time is the time taken for the physiological functioning of all organs to return to their baseline levels. Recovery time can vary among anesthetic agents (usually within 1 to 30 minutes). It is divided into three phases: early/ immediate, intermediate, and late recovery. Early recovery is initiated by the discontinuation of the anesthetic agents, allowing the patient to regain consciousness, recover protective airway reflexes, and resume motor activity [9]. This stage usually varies (from 1 minute up to approximately 15 minutes) depending on the agent used, followed by the retrieval of coordination and loss of dizziness and unsteadiness in movements, known as intermediate recovery. The final late stage of recovery is accomplished once there is a full recovery of coordination and higher intellectual function that may last for hours. Here, early/immediate recovery times (spontaneous eye opening) are taken into consideration in the analysis.

\section{6) Duration (for injected anesthetics only)}

The duration of action of intravenous anesthetic agents refers to the time during which they exert their effects. It generally varies from 5 to 20 minutes among agents, after which they lose their anesthetic effect and spontaneous recovery of consciousness follows. Therefore, to maintain the anesthetic action for the complete duration of an operation, a patient is given a controlled mixture of substances, e.g., a mixture of oxygen, nitrous oxide, and an inhaled anesthetic agent (through inhalation) or usually intravenous medication, e.g., propofol. Thus, it is a common practice to use both intravenous and inhaled agents as a combinatorial drug approach, to prolong the duration of action and reach the desired anesthetic effect. Once the operation is finalized, the administration of anesthetics is withdrawn.

\section{7) Induction dose (for injected anesthetics only)}

The induction dose is the dosage necessary to provide satisfactory induction prior to an operation. Over dosing and under dosing are common in general anesthesia; therefore, the induction dose should be carefully evaluated based on patient data, including age, gender, height, and weight [10].

\section{8) Maintenance dose (for injected anesthetics only)}

Anesthetic administration is a two-step process. Once unconsciousness is rapidly induced by a bolus dose, anesthesia must be maintained to prolong the effects of anesthesia by running an infusion.

\section{9) Washout time (for injected anesthetics only)}

Washout time refers to the period of time that is required for an anesthetic agent to be eliminated from the lung alveoli/ body during recovery. It differs among anesthetics and patients.

\section{Fuzzy PROMETHEE and Application}

The PROMETHEE technique, which is a multi-criteria decision-making technique, was presented in [11] during the 1980s. This method relies on crisp data. In the real-life problems, data are not always crisp values and generally vary within ranges. In this sense, fuzzy logic and its applications allow decision makers to analyze vague conditions and evaluate uncertain data more sensitively than classical models. The fuzzy PROMETHEE method is also a hybrid model that depends on the evaluation of uncertain systems, and it is applied in a variety of fields, including energy, industry, and medicine [12-15], and recent studies have proposed that it be used in clinic $[16,17]$.

The PROMETHEE technique is based on the mutual comparison of each alternative pair with regards to each selected criteria. This model is one of the easiest and most efficient methods in conception and application compared to other multiple-criteria decision-making methods. It is a user-friendly outranking method, which has been successfully implemented to solve real-life planning problems. PROMETHEE-I and PROMETHEE-II give partial and total ranking of the alternatives, respectively, while still satisfying the requirement for simplicity [18]. It requires only two types of information: weights of the criteria considered and the decision-makers preference function when comparing the contribution of the alternatives in terms of each separate criterion [19]. The preference function $\left(p_{j}\right)$ denotes the difference between the evaluations obtained with two alternatives $\left(a_{t}\right.$ and $\left.a_{t}\right)$ with regards to a particular criterion, within a preference degree ranging from 0 to 1 . There are 6 types of preference functions that can be used to implement the PROMETHEE method, namely, usual, U-shaped, V-shaped, level, linear, and Gaussian functions.

The basic steps of the PROMETHEE method [20] are conducted as follows:

Step 1. For each criterion $j$, determine a specific preference function $p_{j}(d)$.

Step 2. Define the weights of each criterion $w_{T}=\left(w_{1}, w_{2}, \ldots\right.$, $\left.w_{k}\right)$. At the discretion of the decision maker, the weights of the criteria can be taken equally only if their importance 
is equal. In addition, normalization can be used for the weights:

$$
\sum_{i=1}^{k} w_{k}=1
$$

Step 3. For all the alternatives, $a_{t}, a_{t^{\prime}} \in A$, define the outranking relation $\pi$ :

$$
\pi\left(a_{t}, a_{t^{\prime}}\right)=\sum_{k=1}^{K} w_{k} \cdot\left[p_{k}\left(f_{k}\left(a_{t}\right)-f_{k}\left(a_{t^{\prime}}\right)\right)\right], A \times A \rightarrow[0,1],
$$

where $p_{k}$ is the weighted average function, $A$ is the alternative, and $A \times A$ denotes the set of all possible alternative pairs. Here, $\pi\left(a_{t}, a_{t}\right)$ denotes the preference index, which is a measure for the intensity of preference of the decision maker for an alternative $a_{t}$ in comparison with an alternative $a_{t^{\prime}}$ while all criteria are considered simultaneously.

Step 4. Determine the leaving and entering outranking flows as follows:

- Leaving (or positive) flow for the alternative $a_{t}$ :

$$
\Phi^{+}\left(a_{t}\right)=\frac{1}{n-1} \sum_{\substack{t^{\prime}=1 \\ t^{\prime} \neq t}}^{n} \pi\left(a_{t}, a_{t^{\prime}}\right)
$$

- Entering (or negative) flow for the alternative $a_{t}$ :

$$
\Phi^{-}\left(a_{t}\right)=\frac{1}{n-1} \sum_{\substack{t^{\prime}=1 \\ t^{\prime} \neq t}}^{n} \pi\left(a_{t^{\prime}}, a_{t}\right)
$$

where $n$ is the number of alternatives. Here, each alternative is compared with $n$-1 number of other alternatives. The leaving flow $\Phi^{+}\left(a_{t}\right)$ expresses the strength of alternative $a_{t} \in A$, while the entering flow $\Phi^{-}\left(a_{t}\right)$ denotes the weakness of alternative $a_{t} \in A$.

Via these outranking flows, the PROMETHEE-I method can provide a partial pre-order of the alternatives, and PROMETHEE-II method can provide a complete pre-order based on the net flow.

Step 5. Determine the partial pre-order on the alternatives of A according to following principle:

In PROMETHEE I, alternative $a_{t}$ is preferred to alternative $a_{t^{\prime}}\left(a_{t} P a_{t^{\prime}}\right)$ if it satisfies one of the following conditions: $\left(a_{t} P a_{t}\right)$ if

$$
\left\{\begin{array}{c}
\Phi^{+}\left(a_{t}\right)>\Phi^{+}\left(a_{t^{\prime}}\right) \text { and } \Phi^{-}\left(a_{t}\right)<\Phi^{-}\left(a_{t^{\prime}}\right) \\
\Phi^{+}\left(a_{t}\right)>\Phi^{+}\left(a_{t^{\prime}}\right) \text { and } \Phi^{-}\left(a_{t}\right)=\Phi^{-}\left(a_{t^{\prime}}\right) \\
\Phi^{+}\left(a_{t}\right)=\Phi^{+}\left(a_{t^{\prime}}\right) \text { and } \Phi^{-}\left(a_{t}\right)<\Phi^{-}\left(a_{t}, a_{t^{\prime}}\right)
\end{array}\right.
$$

When two alternatives $a_{t}$ and $a_{t^{\prime}}$ have the same leaving and entering flows, $a_{t}$ is indifferent to $a_{t^{\prime}}\left(a_{t} I a_{t}\right)$ :

$$
\left(a_{t} I a_{t^{\prime}}\right) \text { if: } \Phi^{+}\left(a_{t}\right)=\Phi^{+}\left(a_{t^{\prime}}\right) \text { and } \Phi^{-}\left(a_{t}\right)=\Phi^{-}\left(a_{t^{\prime}}\right) .
$$

Here, $a_{t}$ is incomparable to $a_{t^{\prime}}\left(a_{t} R a_{t^{\prime}}\right)$ if

$$
\left\{\begin{array}{l}
\Phi^{+}\left(a_{t}\right)>\Phi^{+}\left(a_{t^{\prime}}\right) \text { and } \Phi^{-}\left(a_{t}\right)>\Phi^{-}\left(a_{t^{\prime}}\right) \\
\Phi^{+}\left(a_{t}\right)<\Phi^{+}\left(a_{t^{\prime}}\right) \text { and } \Phi^{-}\left(a_{t}\right)<\Phi^{-}\left(a_{t^{\prime}}\right)
\end{array}\right.
$$

Step 6. Determine the net outranking flow for each alternative:

$$
\Phi^{n e t}\left(a_{t}\right)=\Phi^{+}\left(a_{t}\right)-\Phi^{-}\left(a_{t}\right) .
$$

Via PROMETHEE-II, the complete preorder can be obtained by the net flow and defined as follows:

$$
\begin{aligned}
& a_{t} \text { is preferred to } a_{t^{\prime}}\left(a_{t} P a_{t^{\prime}}\right) \text { if } \Phi^{n e t}\left(a_{t}\right)>\Phi^{n e t}\left(a_{t^{\prime}}\right), \\
& a_{t} \text { is indifferent to } a_{t^{\prime}}\left(a_{t} I a_{t^{\prime}}\right) \text { if } \Phi^{n e t}\left(a_{t}\right)=\Phi^{n e t}\left(a_{t^{\prime}}\right) .
\end{aligned}
$$

Basically, the better alternative is the one that has the higher $\Phi^{\text {net }}\left(a_{t}\right)$ value.

In this study, the fuzzy PROMETHEE technique was applied to evaluate inhaled and injected anesthetics and to identify the "best" inhaled and injected anesthetics according to their physical properties and specific patient groups. To achieve this aim, the aforementioned parameters for inhaled anesthetics (Table 1) and injected anesthetics (Table 2) were collected. These parameters were determined after an extensive literature search. Because some of these parameters do not have crisp values, they were identified by using three values, namely, the lower bound, mode, and upper bound.

Then, these parameters were normalized to obtain triangular fuzzy numbers $(\mathrm{N}, \mathrm{a}, \mathrm{b})$ as seen in Table 3 for inhaled anesthetics and Table 4 for injected anesthetics.

To obtain the importance weight of these parameters, the linguistic importance scale shown in Table 5 was used.

In addition, the Yager index [21] was applied for calculating the magnitude of the fuzzified values by using the following formula: 
Table 1. Parameters of inhaled anesthetics

\begin{tabular}{|c|c|c|c|c|c|}
\hline \multirow{2}{*}{ Inhaled anesthetics } & \multirow{2}{*}{ MAC (\%) } & \multicolumn{2}{|c|}{ Partition coefficient } & \multirow{2}{*}{ Onset of action (sec) } & \multirow{2}{*}{ Recovery time (min) } \\
\hline & & blood:gas & oil:gas & & \\
\hline Isoflurane & $1.15 / 1.15 / 1.52$ & $1.36 / 1.4 / 1.45$ & 91/98/99 & $126 / 283.5 / 547$ & 2.01/9.3/16.96 \\
\hline Desflurane & $5.72 / 6.0 / 6.6$ & $0.42 / 0.42 / 0.57$ & $19 / 26 / 28$ & $58 / 124 / 190$ & $3.6 / 7.2 / 13.69$ \\
\hline Sevoflurane & $1.8 / 2.0 / 2.5$ & $0.6 / 0.65 / 0.74$ & $47 / 47.2 / 65$ & $88 / 170 / 268$ & $5.9 / 8.8 / 16.41$ \\
\hline Enflurane & $1.63 / 1.68 / 1.8$ & $1.8 / 1.9 / 1.91$ & $98 / 98.25 / 98.5$ & $144 / 192 / 240$ & $3.85 / 5.30 / 6.75$ \\
\hline Halothane & $0.75 / 0.75 / 1.01$ & $2.2 / 2.4 / 2.4$ & 224 & $102 / 162 / 222$ & $1.7 / 6.2 / 12.37$ \\
\hline Nitrous oxide & $104 / 104 / 105$ & $0.46 / 0.47 / 0.5$ & 1.4 & $30 / 54 / 60$ & $0.59 / 3.15 / 5.71$ \\
\hline Xenon & $63 / 71 / 72$ & $0.115 / 0.115 / 0.15$ & 1.9 & $50 / 71 / 92$ & $2.3 / 3.2 / 4.8$ \\
\hline
\end{tabular}

Values are identified by using three values, namely, the lower bound, mode, and upper bound.

MAC: minimum alveolar concentration.

Table 2. Parameters of injected anesthetics

\begin{tabular}{|c|c|c|c|c|c|}
\hline Injected anesthetics & Onset of action (sec) & Duration (min) & $\begin{array}{l}\text { Induction dose } \\
(\mathrm{mg} / \mathrm{kg})\end{array}$ & $\begin{array}{l}\text { Maintenance dose } \\
(\mathrm{mg} / \mathrm{kg} / \mathrm{min})\end{array}$ & $\begin{array}{c}\text { Washout time } \\
\qquad\left(\mathrm{T}_{1 / 2 \mathrm{~B}}, \mathrm{~h}\right)\end{array}$ \\
\hline Propofol & $15 / 40 / 60$ & $3 / 5 / 10$ & $1.5 / 2 / 3$ & $0.05 / 0.2 / 0.3$ & $1 / 1.5 / 2$ \\
\hline Ketamine & $10 / 30 / 120$ & $5 / 10 / 25$ & $0.5 / 1.25 / 2$ & $0.01 / 0.02 / 0.03$ & 3 \\
\hline Etomidate & $15 / 30 / 60$ & $3 / 5 / 12$ & $0.2 / 0.3 / 0.6$ & $0.03 / 0.03 / 0.1$ & 3 \\
\hline Methohexital & $0 / 60 / 60$ & $4 / 6 / 7$ & $1 / 1.5 / 2$ & 0.23 & 4 \\
\hline Thiopental & $0 / 30 / 30$ & $5 / 7.5 / 10$ & $3 / 4.5 / 7$ & 0.016 & 12 \\
\hline Midazolam & $30 / 45 / 60$ & $15 / 22.5 / 30$ & $0.025 / 0.1 / 0.3$ & $0.001 / 0.002 / 0.006$ & $2 / 3 / 4$ \\
\hline
\end{tabular}

Values are identified by using three values, namely, the lower bound, mode, and upper bound.

$$
(3 N-a+b) / 3 \text {. }
$$

Then, the visual PROMETHEE program was applied with Gaussian preference functions as seen in Table 6 for the inhaled and injected anesthetics.

In the current study, besides the general ranking of the anesthetics, an imaginary patient was selected with the following condition: a 70-year-old woman to undergo an emergency laparoscopic appendectomy. Comorbidities included severe chronic obstructive pulmonary disease (COPD) as a consequence of a life-long smoking habit, morbid obesity (body mass index, $46 \mathrm{~kg} / \mathrm{m}^{2}$ ), and type II diabetes. This patient would be assigned as Class $4 \mathrm{E}$ [22] according to the ASA physical status classification system. To apply fuzzy PROMETHEE to identify the most appropriate anesthetic to this individual, the weights were first selected and then the $\mathrm{min} /$ max preferences were rearranged after consultation with the anesthesiologists from various hospitals. The linguistic fuzzy scale was defined as shown in Table 7 (note the differences from Table 5 in terms of importance ratings of criteria), and the preferences were assigned as shown in Table 8 for inhaled and injected anesthetics.

\section{Results}

The results showed that nitrous oxide and xenon are among the best inhaled anesthetics in the complete ranking of inhaled anesthetics based on the selected criteria, assigned weights, and set preferences, while halothane is among the least preferred anesthetics. Midazolam, on the other hand, was identified as the best injected anesthetic, followed by etomidate and ketamine, while thiopental is ranked the lowest (Table 9). The results for the specific patient in the example given above are presented in Table 10 for inhaled and injected anesthetics.

\section{Discussion}

Applying the fuzzy PROMETHEE method to identify the most proper anesthesia, results were obtained that could be useful during the decision-making process for anesthesiologists and other clinicians. This study showed that the proposed technique can provide solutions to real-life multi-criteria decision-making problems. The flexibility of 
Table 3. Fuzzified parameters of inhaled anesthetics

\begin{tabular}{|c|c|c|c|c|c|}
\hline \multirow{2}{*}{ Criteria } & \multirow{2}{*}{ MAC } & \multicolumn{2}{|c|}{ Partition } & \multirow{2}{*}{ Onset of action } & \multirow{2}{*}{ Recovery time } \\
\hline & & blood:gas & oil:gas & & \\
\hline \multirow[t]{3}{*}{ Alternatives } & $\mathrm{N}$ & $\mathrm{N}$ & $\mathrm{N}$ & $\mathrm{N}$ & $\mathrm{N}$ \\
\hline & a & a & $\mathrm{a}$ & $\mathrm{a}$ & a \\
\hline & $\mathrm{b}$ & $\mathrm{b}$ & $\mathrm{b}$ & $\mathrm{b}$ & $\mathrm{b}$ \\
\hline \multirow[t]{3}{*}{ Isoflurane } & 0.0062 & 0.1903 & 0.1973 & 0.2683 & 0.2155 \\
\hline & 0.0003 & 0.0052 & 0.1596 & 0.0576 & 0.1148 \\
\hline & 0.0018 & 0.0025 & 0.1435 & 0.0695 & 0.0056 \\
\hline \multirow[t]{3}{*}{ Desflurane } & 0.0322 & 0.0571 & 0.0523 & 0.1174 & 0.1669 \\
\hline & 0.0000 & 0.0033 & 0.0222 & 0.0204 & 0.0136 \\
\hline & 0.0025 & 0.0167 & 0.0440 & 0.0000 & 0.0117 \\
\hline \multirow[t]{3}{*}{ Sevoflurane } & 0.0107 & 0.0884 & 0.0950 & 0.1609 & 0.2039 \\
\hline & 0.0006 & 0.0021 & 0.0893 & 0.0138 & 0.0918 \\
\hline & 0.0024 & 0.0075 & 0.1287 & 0.0046 & 0.0100 \\
\hline \multirow[t]{3}{*}{ Enflurane } & 0.0090 & 0.2583 & 0.1978 & 0.1817 & 0.1228 \\
\hline & 0.0002 & 0.0005 & 0.1865 & 0.0591 & 0.0702 \\
\hline & 0.0004 & 0.0109 & 0.1413 & 0.0335 & 0.0348 \\
\hline \multirow[t]{3}{*}{ Helothane } & 0.0040 & 0.3263 & 0.4509 & 0.1533 & 0.1437 \\
\hline & 0.0002 & 0.0100 & 0.4509 & 0.0172 & 0.0585 \\
\hline & 0.0013 & 0.0154 & 0.4509 & 0.0162 & 0.0176 \\
\hline \multirow[t]{3}{*}{ Nitrous oxide } & 0.5574 & 0.0639 & 0.0028 & 0.0511 & 0.0730 \\
\hline & 0.0267 & 0.0022 & 0.0028 & 0.0009 & 0.0434 \\
\hline & 0.0060 & 0.0009 & 0.0028 & 0.0141 & 0.0015 \\
\hline \multirow[t]{3}{*}{ Xenon } & 0.3805 & 0.0156 & 0.0038 & 0.0672 & 0.0742 \\
\hline & 0.0267 & 0.0009 & 0.0038 & 0.0164 & 0.0411 \\
\hline & 0.0024 & 0.0038 & 0.0038 & 0.0010 & 0.0116 \\
\hline
\end{tabular}

MAC: minimum alveolar concentration, $\mathrm{N}, \mathrm{a}, \mathrm{b}$ : training fuzzy numbers.

the method allows users to add more criteria according to specific needs. For example, one can take the side effects or pharmacodynamics of each drug into account and evaluate the drugs for a specific patient. For a patient with cardiovascular disease, ketamine would not be a good choice because it increases the heart rate, mean arterial pressure [23], cerebral blood flow (CBF), and cerebral metabolic rate of oxygen $\left(\mathrm{CMRO}_{2}\right)$, whereas propofol has no effect on heart rate, and it decreases $\mathrm{CBF}$ and $\mathrm{CMRO}_{2}$ [24]. On the other hand, based on its effect on CBF, propofol might be considered at lower doses for hemodynamically unstable patients. Thus, the choice of the "best" anesthetic depends on a number of criteria, and the proposed method provides a feasible solution.

Anesthesia might have a different effect on elderly people. Post-operative delirium is common in older patients after anesthesia [25]. This effect should be considered carefully for even young or adult patients if they have a neuropsychiatric disorder like schizophrenia [26]. Furthermore, if these older patients are also suffering from neurological diseases, such as Alzheirmer's disease or Parkinson's disease, then the effects of the same drug will be different than they are for healthy adult patients [27]. It is known that the anesthetic dose is reduced with increasing age. Also, geriatric patients are more sensitive to anesthetic drugs, and it takes more time for them to emerge from general anesthesia in comparison to other patients. This is mainly because of the progressive decline in the CNS. Furthermore, overall decreased muscle mass lets the drugs stay in the body longer and causes an increase in the washout time.

On the other hand, cardiac or lung diseases, as in the patient-specific example given in this study, require a different anesthetic dose than that usually given, and COPD causes 
Table 4. Fuzzified parameters of injected anesthetics

\begin{tabular}{|c|c|c|c|c|c|}
\hline Criteria & Onset of action & Duration & Induction dose & Maintenance dose & Washout time \\
\hline \multirow[t]{3}{*}{ Alternatives } & $\mathrm{N}$ & $\mathrm{N}$ & $\mathrm{N}$ & $\mathrm{N}$ & $\mathrm{N}$ \\
\hline & $\mathrm{a}$ & $\mathrm{a}$ & $\mathrm{a}$ & $\mathrm{a}$ & $\mathrm{a}$ \\
\hline & $\mathrm{b}$ & $\mathrm{b}$ & $\mathrm{b}$ & $\mathrm{b}$ & $\mathrm{b}$ \\
\hline \multirow[t]{3}{*}{ Propofol } & 0.1702 & 0.0893 & 0.2073 & 0.4016 & 0.0566 \\
\hline & 0.0441 & 0.0036 & 0.0337 & 0.1478 & 0.2767 \\
\hline & 0.0164 & 0.0171 & 0.0059 & 0.2865 & 0.2767 \\
\hline \multirow[t]{3}{*}{ Ketamine } & 0.1277 & 0.1786 & 0.1295 & 0.0402 & 0.1132 \\
\hline & 0.0152 & 0.0357 & 0.0492 & 0.0697 & 0.1132 \\
\hline & 0.1800 & 0.0874 & 0.0047 & 0.0286 & 0.1132 \\
\hline \multirow[t]{3}{*}{ Etomidate } & 0.1277 & 0.0893 & 0.0311 & 0.0602 & 0.1132 \\
\hline & 0.0866 & 0.0036 & 0.0010 & 0.2694 & 0.1132 \\
\hline & 0.0262 & 0.0384 & 0.0092 & 0.1691 & 0.1132 \\
\hline \multirow[t]{3}{*}{ Methohexital } & 0.2553 & 0.1071 & 0.1554 & 0.4618 & 0.1509 \\
\hline & 0.2553 & 0.0071 & 0.0052 & 0.4618 & 0.1509 \\
\hline & 0.1015 & 0.0327 & 0.0212 & 0.4618 & 0.1509 \\
\hline \multirow[t]{3}{*}{ Thiopental } & 0.1277 & 0.1339 & 0.4663 & 0.0321 & 0.4528 \\
\hline & 0.1277 & 0.0089 & 0.0156 & 0.0321 & 0.4528 \\
\hline & 0.0507 & 0.0275 & 0.0035 & 0.0321 & 0.4528 \\
\hline \multirow[t]{3}{*}{ Midazolam } & 0.1915 & 0.4018 & 0.0104 & 0.0040 & 0.1132 \\
\hline & 0.2371 & 0.0268 & 0.0063 & 0.0070 & 0.5535 \\
\hline & 0.0376 & 0.0826 & 0.0098 & 0.0097 & 0.5535 \\
\hline
\end{tabular}

$\mathrm{N}$, a, b: training fuzzy numbers.

Table 5. Linguistic fuzzy scale for the importance of the parameters

\begin{tabular}{lcc}
\hline $\begin{array}{c}\text { Linguistic scale } \\
\text { for evaluation }\end{array}$ & $\begin{array}{c}\text { Triangular fuzzy } \\
\text { scale }\end{array}$ & $\begin{array}{c}\text { Importance ratings of } \\
\text { criteria }\end{array}$ \\
\hline Very high (VH) & $(0.75,1,1)$ & $\begin{array}{c}\text { MAC, onset of action, } \\
\text { recovery time }\end{array}$ \\
Important (H) & $(0.50,0.75,1)$ & $\begin{array}{c}\text { Blood:gas partition coef- } \\
\text { ficient, oil:gas partition } \\
\text { coefficient, washout time }\end{array}$ \\
Medium (M) & $(0.25,0.50,0.75)$ & $\begin{array}{c}\text { Duration, induction dose, } \\
\text { maintenance dose }\end{array}$ \\
Low (L) & $(0,0.25,0.50)$ & - \\
Very low (VL) & $(0,0,0.25)$ & - \\
\hline
\end{tabular}

MAC: minimum alveolar concentration.

delay in the emergence process. Therefore, the duration parameter preference was maintained as "min", and the linguistic scale for recovery time and onset of action (i.e. desiring fast-acting drugs) were set as "very high". The application can be implemented by modifying the associated parameters and their weights accordingly. Similar situations exist for patients with neuropsychiatric disorders, where the effects of anesthetics on the neurotransmitter and receptor systems may trigger the onset of diseases.

Cost can be considered as a criteria because nearly 100,000 people per day across the United States are put under some form of anesthesia, and nearly 230 million surgeries are performed every year all over the world. Although it was not included as a parameter in the current study, it will have an effect on hospital management, where this parameter can be set according to its importance to a specific institution. Also, onset of action may be important for the surgeon for a quick and short operation, and then its importance has to be set properly.

Furthermore, side effects should be included as another criteria in future studies. Post-operative nausea and vomiting are common effects of many anesthetics. Others include sore throat, hoarseness, muscle aches, itching, shivering, confusion (post-operative delirium), and finally, temporary memory loss, which is more common in the elderly. Heart attack and stroke can be considered as risks for older patients un- 
Table 6. Preferences for inhaled and injected anesthetics

\begin{tabular}{|c|c|c|c|c|}
\hline & \multicolumn{2}{|c|}{ Inhaled anesthetics } & \multicolumn{2}{|c|}{ Injected anesthetics } \\
\hline & $\min / \max$ & Weight & $\min / \max$ & Weight \\
\hline MAC (\%) & $\max$ & 0.92 & - & - \\
\hline \multicolumn{5}{|l|}{ Partition coefficient } \\
\hline Blood:Gas & $\min$ & 0.75 & - & - \\
\hline Oil:Gas & $\min$ & 0.75 & - & - \\
\hline Onset of action (sec) & $\min$ & 0.92 & $\min$ & 0.92 \\
\hline Recovery time (sec) & $\min$ & 0.92 & - & - \\
\hline Duration (min) & - & - & $\max$ & 0.50 \\
\hline Induction dose $(\mathrm{mg} / \mathrm{kg})$ & - & - & $\min$ & 0.50 \\
\hline Maintenance dose $(\mathrm{mg} / \mathrm{kg} / \mathrm{min})$ & - & - & $\min$ & 0.50 \\
\hline Washout time $\left(\mathrm{T}_{1 / 2 \mathrm{~B}}, \mathrm{~h}\right)$ & - & - & $\min$ & 0.75 \\
\hline
\end{tabular}

MAC: minimum alveolar concentration.

Table 7. Linguistic fuzzy scale for the importance of parameters for a class $4 \mathrm{E}$ patient

\begin{tabular}{ccl}
\hline Linguistic scale for evaluation & Triangular fuzzy scale & \multicolumn{1}{c}{ Importance ratings of criteria } \\
\hline Very high $(\mathrm{VH})$ & $(0.75,1,1)$ & Onset of action, recovery time, washout time, duration \\
Important $(\mathrm{H})$ & $(0.50,0.75,1)$ & Induction dose, maintenance dose, MAC \\
Medium (M) & $(0.25,0.50,0.75)$ & Blood:gas partition coefficient, oil:gas partition coefficient \\
Low (L) & $(0,0.25,0.50)$ & - \\
Very low (VL) & $(0,0,0.25)$ & - \\
\hline
\end{tabular}

MAC: minimum alveolar concentration.

Table 8. Preferences for inhaled and injected anesthetics for a class 4E patient

\begin{tabular}{|c|c|c|c|c|}
\hline & \multicolumn{2}{|c|}{ Inhaled anesthetics } & \multicolumn{2}{|c|}{ Injected anesthetics } \\
\hline & $\min / \max$ & Weight & $\min / \max$ & Weight \\
\hline MAC (\%) & $\min$ & 0.75 & - & - \\
\hline \multicolumn{5}{|l|}{ Partition coefficient } \\
\hline Blood:Gas & $\min$ & 0.50 & - & - \\
\hline Oil:Gas & $\min$ & 0.50 & - & - \\
\hline Onset of action (sec) & $\min$ & 0.92 & $\min$ & 0.92 \\
\hline Recovery time (sec) & $\min$ & 0.92 & - & - \\
\hline Duration (min) & - & - & $\min$ & 0.92 \\
\hline Induction dose $(\mathrm{mg} / \mathrm{kg})$ & - & - & $\min$ & 0.75 \\
\hline Maintenance dose $(\mathrm{mg} / \mathrm{kg} / \mathrm{min})$ & - & - & $\min$ & 0.75 \\
\hline Washout time $\left(\mathrm{T}_{1 / 2 \mathrm{~B}}, \mathrm{~h}\right)$ & - & - & $\min$ & 0.92 \\
\hline
\end{tabular}

MAC: minimum alveolar concentration.

dergoing long procedures. Common side effects of ketamine include hallucinations, which should be taken into account during preoperative evaluation for people with mental disorders, such as schizophrenia. Moreover, anesthetics are not administered in isolation, and usually more than one drug is required to reach the state of general anesthesia. Therefore, in further studies, the effect of combinations of anesthetics on the selected procedures will also be investigated for a 
Table 9. Complete ranking of inhaled and injected anesthetics

\begin{tabular}{|c|c|c|c|c|c|}
\hline & Rank & Alternatives & $\begin{array}{c}\text { Positive outranking } \\
\text { flow } \\
\end{array}$ & $\begin{array}{c}\text { Negative outranking } \\
\text { flow }\end{array}$ & Net flow \\
\hline \multirow[t]{7}{*}{ Inhaled anesthetics } & 1 & Nitrous oxide & 0.0039 & 0.0000 & 0.0039 \\
\hline & 2 & Xenon & 0.0023 & 0.0001 & 0.0022 \\
\hline & 3 & Desflurane & 0.0006 & 0.0008 & -0.0002 \\
\hline & 4 & Sevoflurane & 0.0004 & 0.0010 & -0.0006 \\
\hline & 5 & Enflurane & 0.0002 & 0.0013 & -0.0012 \\
\hline & 6 & Isoflurane & 0.0001 & 0.0015 & -0.0014 \\
\hline & 7 & Halothane & 0.0000 & 0.0028 & -0.0027 \\
\hline \multirow[t]{6}{*}{ Injected anesthetics } & 1 & Midazolam & 0.0023 & 0.0000 & 0.0023 \\
\hline & 2 & Etomidate & 0.0014 & 0.0002 & 0.0012 \\
\hline & 3 & Ketamine & 0.0012 & 0.0002 & 0.0010 \\
\hline & 4 & Propofol & 0.0006 & 0.0016 & -0.0010 \\
\hline & 5 & Methohexital & 0.0004 & 0.0017 & -0.0013 \\
\hline & 6 & Thiopental & 0.0007 & 0.0029 & -0.0022 \\
\hline
\end{tabular}

Table 10. Complete ranking of inhaled and injected anesthetics for a class $4 \mathrm{E}$ patient

\begin{tabular}{|c|c|c|c|c|c|}
\hline & Rank & Alternatives & $\begin{array}{l}\text { Positive outranking } \\
\text { flow }\end{array}$ & $\begin{array}{c}\text { Negative outranking } \\
\text { flow }\end{array}$ & Net flow \\
\hline \multirow[t]{7}{*}{ Inhaled anesthetics } & 1 & Desflurane & 0.0013 & 0.0001 & 0.0012 \\
\hline & 2 & Sevoflurane & 0.0011 & 0.0002 & 0.0010 \\
\hline & 3 & Enflurane & 0.0009 & 0.0004 & 0.0005 \\
\hline & 4 & Isoflurane & 0.0009 & 0.0007 & 0.0002 \\
\hline & 5 & Xenon & 0.0011 & 0.0012 & -0.0001 \\
\hline & 6 & Halothane & 0.0008 & 0.0019 & -0.0011 \\
\hline & 7 & Nitrous oxide & 0.0010 & 0.0027 & -0.0017 \\
\hline \multirow[t]{6}{*}{ Injected anesthetics } & 1 & Etomidate & 0.0018 & 0.0000 & 0.0018 \\
\hline & 2 & Ketamine & 0.0014 & 0.0001 & 0.0012 \\
\hline & 3 & Midazolam & 0.0016 & 0.0010 & 0.0006 \\
\hline & 4 & Propofol & 0.0008 & 0.0016 & -0.0007 \\
\hline & 5 & Methohexital & 0.0006 & 0.0017 & -0.0010 \\
\hline & 6 & Thiopental & 0.0009 & 0.0027 & -0.0018 \\
\hline
\end{tabular}

more accurate evaluation.

This study has shown that fuzzy PROMETHEE can be used to evaluate general anesthetics and to select the most appropriate one for individual needs. Parameters and weights that influence the selection of are anesthetic were decided upon by consulting experts in the field of anesthesiology. Fuzzy PROMETHEE can be used to determine the optimal anesthetic among possible alternatives.

With this method, general anesthetics can be evaluated accurately and systematically including as many parameters as needed. The fuzzy PROMETHEE application is more efficient and effective than other methods. Fuzzy data that is not crisp is part of the decision process and there are too many parameters to be set properly with other methods; however, fuzzy PROMETHEE can handle this kind of data very well. In fact, there is only one existing method in which anesthetists perform a preoperative assessment by reviewing the patient medical history and overall physical performance and select the most appropriate drugs based on experience. 


\section{Conflict of Interest}

No potential conflict of interest relevant to this article was reported.

\section{Acknowledgments}

I would like to thank Ms. Berna Uzun, Ms. Gulcem Altinoglu for their contributions, and Prof. Dr. Murat Gunduz, Assoc. Prof. Dr. Dilber Uzun Ozsahin and Assoc. Prof. Dr. Greta S. P. Mok for helpful discussions during this study.

\section{ORCID}

Ilker Ozsahin (http://orcid.org/0000-0002-3141-6805)

\section{References}

1. Lemke TL, Williams DA. Foye's principles of medicinal chemistry. 6ed ed. Philadelphia (PA): Lippincott Williams \& Wilkins; 2008.

2. McCartney CJ, Choi S. Does anaesthetic technique really matter for total knee arthroplasty? Br J Anaesth 2013;111(3):331-3.

3. Fischer SP. Development and effectiveness of an anesthesia preoperative evaluation clinic in a teaching hospital. Anesthesiology 1996;85(1):196-206.

4. Tuzkaya G, Gulsun B, Kahraman C, Ozgen D. An integrated fuzzy multi-criteria decision making methodology for material handling equipment selection problem and an application. Expert Syst Appl 2010;37(4):285363.

5. White D. Uses of MAC. Br J Anaesth 2003;91(2):167-9.

6. Magee P, Tooley M. The physics, clinical measurement and equipment of anaesthetic practice for the FRCA. 2nd ed. Oxford, UK: Oxford University Press; 2011.

7. Esper T, Wehner M, Meinecke CD, Rueffert H. Blood/ Gas partition coefficients for isoflurane, sevoflurane, and desflurane in a clinically relevant patient population. Anesth Analg 2015;120(1):45-50.

8. Battino R. The Ostwald coefficient of gas solubility. Fluid Phase Equilib 1984;15:231-40.

9. Misal US, Joshi SA, Shaikh MM. Delayed recovery from anesthesia: a postgraduate educational review. Anesth Essays Res 2016;10(2):164-72.

10. Kumar A, Anand S, Yaddanapudi LN. Fuzzy model for estimating induction dose for general anesthesia. J Sci Ind Res 2006;65(4):325-8.
11. Vincke JP, Brans P. A preference ranking organization method. The PROMETHEE method for MCDM. Manag Sci 1985;31(6):647-56.

12. Goumas M, Lygerou V. An extension of the PROMETHEE method for decision making in fuzzy environment: ranking of alternative energy exploitation projects. Eur J Oper Res 2000;123(3):606-13.

13. Ozgen A, Tuzkaya G, Tuzkaya UR, Ozgen D. A multicriteria decision making approach for machine tool selection problem in a fuzzy environment. Int J Comput Intell Syst 2011;4(4):431-45.

14. Ozsahin DU, Uzun B, Sani M, Ozsahin I. Evaluating $\mathrm{X}$-ray based medical imaging devices with fuzzy preference ranking organization method for enrichment evaluations. Int J Adv Comput Sci Appl 2018;9(3):7-10.

15. Maisaini M, Uzun B, Ozsahin I, Uzun D. Evaluating lung cancer treatment techniques using fuzzy PROMETHEE approach. In: Aliev R, Kacprzyk J, Pedrycz W, Jamshidi M, Sadikoglu F, editors. 13th International Conference on Theory and Applications of Fuzzy Systems and Soft Computing. Cham, Switzerland: Springer; 2018. p. 209-15.

16. Ozsahin I, Abebe ST, Mok GS. A multi-criteria decisionmaking approach for schizophrenia treatment techniques. Arch Psychiatry Psychother 2020;2:52-61.

17. Ozsahin I, Ozsahin DU, Maisaini M, Mok GS. Fuzzy PROMETHEE analysis of leukemia treatment techniques. World Cancer Res J 2019;6:e1315.

18. Ulengin F, Topcu YI, Sahin SO. An integrated decision aid system for Bosphorus water-crossing problem. Eur J Oper Res 2001;134(1):179-92.

19. Macharis C, Springael J, De Brucker K, Verbeke A. PROMETHEE and AHP: the design of operational synergies in multicriteria analysis.: Strengthening PROMETHEE with ideas of AHP. Eur J Oper Res 2004;153(2):307-17.

20. Geldermann J, Spengler T, Rentz O. Fuzzy outranking for environmental assessment. Case study: iron and steel making industry. Fuzzy Sets Syst 2000;115(1):45-65.

21. Yager RR. A procedure for ordering fuzzy subsets of the unit interval. Inf Sci 1981;24(2):143-61.

22. Doyle DJ, Goyal A, Bansal P, Garmon EH. American Society of Anesthesiologists Classification (ASA Class) [Internet]. Treasure Island (FL): StatPearls Publishing; 2020 [cited at $2020 \mathrm{Jul}$ 25]. Available from: https://www. ncbi.nlm.nih.gov/books/NBK441940/.

23. Perret-Guillaume C, Joly L, Benetos A. Heart rate as a risk factor for cardiovascular disease. Prog Cardiovasc Dis 2009;52(1):6-10. 
24. Sikorski RA, Koerner AK, Fouche-Weber LY, Galvagno SM. Choice of general anesthetics for trauma patients. Curr Anesthesiol Rep 2014;4(3):225-32.

25. Funder KS, Steinmetz J, Rasmussen LS. Anaesthesia for the patient with dementia undergoing outpatient surgery. Curr Opin Anaesthesiol 2009;22(6):712-7.
26. Constance LSL, Lansing MG, Khor FK, Muniandy RK. Schizophrenia and anaesthesia. BMJ Case Rep 2017;2017:bcr2017221659.

27. Papon MA, Whittington RA, El-Khoury NB, Planel E. Alzheimer's disease and anesthesia. Front Neurosci 2011;4:272. 